\title{
Effects of auxin derivatives on phenotypic plasticity and stress tolerance in five species of the green alga Desmodesmus (Chlorophyceae, Chlorophyta)
}

\author{
Wei-Jiun Lin ${ }^{1}$, Han-Chen Ho ${ }^{2}$, Sheng-Chang Chu ${ }^{1}$, Jui-Yu Chou ${ }^{\text {Corresp. } 1}$ \\ 1 Department of Biology, National Changhua University of Education, Changhua, Taiwan \\ 2 Department of Anatomy, Tzu Chi University, Hualien, Taiwan \\ Corresponding Author: Jui-Yu Chou \\ Email address: jackyjau@cc.ncue.edu.tw
}

Green microalge of the genus Desmodesmus are characterized by a high degree of phenotypic plasticity, allowing them to be truly cosmopolitan and withstand environmental fluctuations. This flexibility enables Desmodesmus to produce a phenotype-environment match across a range of environments broader compared to algae with more fixed phenotypes. Indoles and their derivatives are a well-known crucial class of heterocyclic compounds and are widespread in different species of plants, animals, and microorganisms. Indole-3-acetic acid (IAA) is the most common, naturally occurring, plant hormone of the auxin class. IAA may behave as a signaling molecule in microorganisms, and the physiological cues of IAA may also trigger phenotypic plasticity responses in Desmodesmus. In this study, we demonstrated that the changes in colonial morphs of five species of the green alga Desmodesmus were specific to IAA but not to the chemically more stable synthetic auxins, naphthalene-1-acetic acid and 2,4-dichlorophenoxyacetic acid. Moreover, inhibitors of auxin biosynthesis and polar auxin transport inhibited cell division. Notably, different algal species (even different intraspecific strains) exhibited phenotypic plasticity different to that correlated to IAA. Thus, the plasticity involving individual-level heterogeneity in morphological characteristics may be crucial for microalgae to adapt to changing or novel conditions, and IAA treatment potentially increases the tolerance of Desmodesmus algae to several stress conditions. In summary, our results provide circumstantial evidence for the hypothesized role of IAA as a diffusible signal in the communication between the microalga and microorganisms. This information is crucial for elucidation of the role of plant hormones in planktonecology. 
1 Effects of auxin derivatives on phenotypic plasticity and stress tolerance in five species of 2 the green alga Desmodesmus (Chlorophyceae, Chlorophyta)

3

4 Wei-Jiun Lin ${ }^{1}$, Han-Chen $\mathrm{Ho}^{2}$, Sheng-Chang $\mathrm{Chu}^{1}$ \& Jui-Yu Chou ${ }^{1 *}$

$5{ }^{1}$ Department of Biology, National Changhua University of Education, Changhua 50007, Taiwan

6 2Department of Anatomy, Tzu Chi University, Hualien 97004, Taiwan

7

8 Corresponding author.

9 Correspondence to Jui-Yu Chou

10 Tel: +886-4-7232105 Ext. 3426; Fax: 886-4-7211156; Email: jackyjau@cc.ncue.edu.tw 


\section{Abstract}

13 Green microalgae of the genus Desmodesmus are characterized by a high degree of phenotypic 14 plasticity (i.e. colony morphology), allowing them to be truly cosmopolitan and withstand environmental fluctuations. This flexibility enables Desmodesmus to produce a phenotypeenvironment match across a range of environments broader compared to algae with more fixed phenotypes. Indoles and their derivatives are a well-known crucial class of heterocyclic compounds and are widespread in different species of plants, animals, and microorganisms. Indole-3-acetic acid (IAA) is the most common, naturally occurring, plant hormone of the auxin 20 class. IAA may behave as a signaling molecule in microorganisms, and the physiological cues of IAA may also trigger phenotypic plasticity responses in Desmodesmus. In this study, we

22 demonstrated that the changes in colonial morphs (cells per coenobium) of five species of the 23 green alga Desmodesmus were specific to IAA but not to the chemically more stable synthetic 24 auxins, naphthalene-1-acetic acid and 2,4-dichlorophenoxyacetic acid. Moreover, inhibitors of 25 auxin biosynthesis and polar auxin transport inhibited cell division. Notably, different algal species (even different intraspecific strains) exhibited phenotypic plasticity different to that 27 correlated to IAA. Thus, the plasticity involving individual-level heterogeneity in morphological characteristics may be crucial for microalgae to adapt to changing or novel conditions, and IAA treatment potentially increases the tolerance of Desmodesmus algae to several stress conditions. In summary, our results provide circumstantial evidence for the hypothesized role of IAA as a diffusible signal in the communication between the microalga and microorganisms. This information is crucial for elucidation of the role of plant hormones in plankton ecology.

Keywords Coenobial algae $\cdot$ Desmodesmus $\cdot$ Indole derivatives $\cdot$ Microalgae $\cdot$ Phenotypic 35 plasticity 


\section{Introduction}

38 Phenotypic plasticity can be broadly defined as the capacity of a single genotype to exhibit variable phenotypes in different environments and implies that a species can conquer diverse environments. Phenotypic plasticity refers to some of the changes in an organism's behavior, morphology and physiology in response to a unique environment. A well-known example of phenotypic plasticity is changes in multicelled structures in coenobial algae. In these algae, colonies reproduce asexually by successive divisions of the protoplast within the parent cell wall, and when progeny are released, the parent wall remains. Daughter colony may be morphologically identical to the parent, or they may exhibit remarkable phenotypic plasticity. Most studies on phenotypic plasticity in coenobial algae have been conducted considering morphological responses to an abiotic factor. Neustupa and Hodač (2005) demonstrated that morphological plasticity of Pediastrum duplex var. duplex is related to the $\mathrm{pH}$ dynamics of freshwater lakes. Peña-Castro et al. (2004) also reported the phenotypic plasticity in Scenedesmus incrassatulus in response to heavy metal stress. However, microalgae are typically associated with other microorganisms, such as zooplankton, fungi, and bacteria. Thus, studies on phenotypic plasticity of the coenobial algae have increased in number and broadened their scope from the focus on abiotic factors to biotic ones. Hessen and Van Donk (1993) first indicated that the presence of the grazing pressure from water flea (Daphnia magna) can induce colony formation in Scenedesmus algae. Furthermore, Lurling and his colleague proved that the induced colony formation in the presence of herbivores is considered a strategy more efficient than constitutive defenses under variable grazing risk (Lürling \& Van Donk, 1996; Lürling, 2003). $\mathrm{Wu}$ et al. (2013) further revealed that the number of cells per coenobium of Scenedesmus increased with the population density of Daphnia growth, thus indicating a grazer densitydependent response.

Auxins, which constitute a class of plant hormones, have previously been suggested to regulate physiological responses and gene expression in microorganisms (Spaepen et al., 2007). Indole-3-acetic acid (IAA) is one of the most physiologically active auxins that can be produced by numerous microbial species (Spaepen et al., 2007; Fu et al., 2015). Furthermore, phylogenetic analyses have revealed that IAA biosynthetic pathways evolved independently in plants, bacteria, algae, and fungi (Fu et al., 2015). The convergent evolution of IAA production leads to the hypothesis that natural selection might have favored IAA as a widespread physiological code in these microorganisms and their interactions. In natural water bodies, the crucial physical associations and biochemical interactions between microalgae and other microorganisms are generally well recognized (Natrah et al., 2014). Piotrowska-Niczyporuk and Bajguz (2014) found that IAA plays a crucial role in the growth and metabolism of Chlorella vulgaris during a 72hour culture period. Jusoh et al. (2015) indicated that IAA can induce changes in oil content, 
73 fatty acid profiles, and expression of four genes responsible for fatty acid biosynthesis in $C h$. 74 vulgaris at early stationary growth phase. In addition, the significance of these interactions in 75 algal phenotypic plasticity has attracted considerable scientific attention (Lürling \& Van Donk, 76 1996; Lürling \& Van Donk, 2000; Lürling 2003). Furthermore, IAA has been detected in some 77 species of Scenedesmaceae microalgae (Mazur et al., 2001; Prieto et al., 2011). We previously 78 used IAA as a signal molecule in microorganisms to simulate a selection pressure caused by 79 interspecific competition. The results indicated that the mean number of cells per particle of 80 Desmodesmus opoliensis and D. komarekii decreased gradually as the IAA concentration increased gradually. The proportion of Desmodesmus unicells in monocultures increased with IAA concentration. We also demonstrated that these unicells exhibited a lower tendency to sedimentation than did large cells and that shrinkage may facilitate nutrient uptake and light capture (Chung et al., 2018). However, whether other coenobial algal species of Desmodesmus use the same strategy to overcome stress remains unknown. Hence, the objective of the present study was to compare the effects of IAA at different concentrations on phenotypic responses in different Desmodesmus species. Moreover, to address the auxin specificity of these processes and obtain an insight into the complex auxin-related regulatory mechanism(s) in algal physiology, we have selected a group of compounds called "auxin analogs," such as synthetically produced naphthalene-1-acetic acid (NAA) and 2,4-dichlorophenoxyacetic acid (2,4-D), which are structurally related to IAA. We thus aim to determine the differential effects of auxins and auxinlike compounds on the morphological responses of these coenobial algae. In addition, we investigated the effects of inhibitors of auxin biosynthesis and auxin transport in Desmodesmus. Here, 4-biphenylboronic acid (BBo), a potent YUCCA enzyme inhibitor and an Arabidopsis growth inhibitor, and 2,3,5-triiodobenzoic acid (TIBA), a polar auxin transport inhibitor, were used (Dhonukshe et al. 2008; Kakei et al. 2015). To elucidate the physiological changes induced by phytohormone treatment, we also investigated whether IAA pretreatment promotes an enhanced stress-tolerant phenotype. The obtained results are crucial for elucidating the role of plant hormones in microalgal physiology.

\section{Materials and Methods}

\section{Isolation and Culture of Microalgae}

104

105

106

107
The algal strains used here were isolated from natural water bodies in Central Taiwan. Water samples with visible microalgal population were centrifuged at $3000 \times g$ for 10 minutes at room temperature to concentrate the cells and spread onto CA agar plates (with $0.8 \% \mathrm{w} / \mathrm{v}$ agar) (for more details see Supplementary Materials). For isolating an axenic single colony from field water samples, the streak plate method was used. The algae were cultured in CA medium. Isolated algal cells were stored at $-80^{\circ} \mathrm{C}$ in $15 \%-20 \%$ glycerol. For each experiment, the alga 
109 was cultured axenically in liquid CA medium at $125 \mathrm{rpm}$ in a tube rotator and grown at $25^{\circ} \mathrm{C}$ 110 under cool white fluorescent light (approximately $46.30 \mu \mathrm{mol} \mathrm{m}^{-2} \mathrm{~s}^{-1}$ ) with a 14:10-h light-dark

111 period. Each algal culture sample was observed for cellular growth rates by measuring the 112 optical density at $680 \mathrm{~nm}$. The regression equation between cell density $\left(\mathrm{y} \times 10^{5} / \mathrm{mL}\right)$ and $\mathrm{OD}_{685}$ 113 (x) was derived as $\mathrm{y}=162.1 \mathrm{x}+1.3463\left(\mathrm{r}^{2}=99.34 \%\right)$ (Qian et al., 2009).

114

\section{Algae Identification}

116 The algal cells were harvested by centrifugation at $3000 \times g$ at $25^{\circ} \mathrm{C}$ for 10 minutes. The genomic 117 DNA used for analysis was isolated using AccuPrep GMO DNA Extraction Kit (Bioneer, Korea).

118

119

120

121

122

123

124

125

126

127

128

129

130

131

132

133

134

135

136

137

138

139

140

141

142

143

144

The 18S rDNA was amplified through PCR by using the following primers: 18S forwardTTTCTGCCCTATCAACTTTCGATG and 18S reverse-TACAAAGGGCAGGGACGTAAT, which yielded a fragment of approximately 1200 bp (Pan et al., 2011). The PCR conditions were as follows: initial denaturation at $96^{\circ} \mathrm{C}$ for 4 minutes; 36 cycles of denaturation at $96^{\circ} \mathrm{C}$ for $30 \mathrm{~s}$, annealing at $50^{\circ} \mathrm{C}$ for $30 \mathrm{~s}$, and extension at $72^{\circ} \mathrm{C}$ for 1 minutes; and final extension at $72^{\circ} \mathrm{C}$ for 6 minutes. The ITS1-5.8S-ITS2 rDNA was amplified using the primers ITS forward1 (ACCTAGAGGAAGGAGAAGTCGTAA) and reverse1 (TTCCTCCGCTTATTGATATGC), which yielded a fragment of approximately $1200 \mathrm{bp}$ (Pan et al., 2011). The PCR conditions were as follows: initial denaturation at $96^{\circ} \mathrm{C}$ for 4 minutes; 36 cycles of denaturation at $96^{\circ} \mathrm{C}$ for $30 \mathrm{~s}$, annealing at $48^{\circ} \mathrm{C}$ for $30 \mathrm{~s}$, and extension at $72^{\circ} \mathrm{C}$ for 1 minutes; and final extension at $72^{\circ} \mathrm{C}$ for 6 minutes. DNA sequencing was performed by Tri-I Biotech, Inc. (Taipei, Taiwan). The Basic Local Alignment Search Tool was used to find regions of local similarity between sequences on the website of the National Center for Biotechnology Information (http://www.ncbi.nlm.nih.gov). The voucher specimens of algal strains used in this study are deposited in the Freshwater Algae Culture Collection at the Institute of Hydrobiology, Hubei Province, China (http://algae.ihb.ac.cn/). The detailed information of each strain is provided in Supplementary Table 1. Any requests can be addressed to the corresponding author.

\section{Experimental Design}

Solutions containing different concentrations of phytohormones (IAA, NAA, and 2,4-D) and auxin-related compounds (4-biphenylboronic acid and 2,3,5-triiodobenzoic acid) were prepared to investigate their influence on the growth and morphological plasticity of Desmodesmus strains. The concentrations of each phytohormone and compounds used in each experiment depended on the sensitivity of each species. The initial algal density in each culture was approximately $8.24 \times$ $10^{3}$ cells $\cdot \mathrm{mL}^{-1}$. Algae were harvested after each experiment, and the proportions of differentcelled populations were calculated under an optical microscope (DMRB, Leica, Germany). The proportion of different algal populations (including unicellular; two-, four-, and eight-celled; and 
145 other colonial morphs) were calculated, and the mean numbers of cells in different morphotypes

146 were calculated. The numbers of cells per coenobium were counted by dividing the total cell

147 number by the number of coenobia.

148

149

150

151

152

153

154

155

156

157

158

159

160

161

162

163

164

165

166

167

168

169

170

171

172

173

174

175

176

177

178

179

180

\section{Transmission Electron Microscopy}

All specimens were prefixed in $2.5 \%$ glutaraldehyde $/ 0.1 \mathrm{M}$ sodium cacodylate buffer $(\mathrm{pH} 7.3)$ containing $1 \%$ tannic acid at $4{ }^{\circ} \mathrm{C}$ overnight. After washing in $0.1 \mathrm{M}$ sodium cacodylate buffer with $5 \%$ sucrose for 15 minutes three times, specimens were postfixed with $1 \%$ osmium tetroxide in $0.1 \mathrm{M}$ sodium cacodylate buffer at $4^{\circ} \mathrm{C}$ overnight. Specimens were then washed in buffer, en bloc stained with $2 \%$ aqueous uranyl acetate, dehydrated through a graded series of ethanol and two times with 100\% acetone. Specimens were infiltrated with Spurr resin overnight and embedded in fresh Spurr resin the next day. Serial ultrathin sections of approximately $70 \mathrm{~nm}$ were cut with a diamond knife on a Leica Ultracut R ultramicrotome (Leica, Heerbrugg, Switzerland). Ultrathin sections were collected on Formvar-coated copper slot grids (type: GS2x1, Cat. \#: G2010-Cu, Electron Microscopy Sciences) and examined with a Hitachi H-7500 transmission electron microscope (Hitachi, Tokyo, Japan) at $80 \mathrm{kV}$. Images were recorded using a $2048 \times 2048$ Macrofire monochrome CCD camera (Optronics, Goleta, CA, USA).

\section{Stress Tests}

The log-phase algal cells were treated with $300 \mu \mathrm{M}$ IAA for $24 \mathrm{~h}$. The culture samples were harvested; the cells were then washed with CA medium and resuspended in the CA medium with different treatments. The initial algal density in each culture was approximately $9.86 \times 10^{6}$ cells $\cdot \mathrm{mL}^{-1}$. For osmotic shock test, the cells were incubated in the CA medium with $0.5 \mathrm{M} \mathrm{NaCl}$. For the effects of $\mathrm{pH}$ value, the culture samples were resuspended in $\mathrm{CA}$ medium at $\mathrm{pH} 3.0$ (adjusted with $\mathrm{HCl}$ ) or at $\mathrm{pH} 8.0$ (adjusted with $\mathrm{NaOH}$ ). For oxidative stress, the cells were exposed to hydrogen peroxide at final concentration of $5 \mathrm{mM}$. The cell suspensions subjected to the aforementioned treatments were shaken at $25^{\circ} \mathrm{C}$ for 15 or 30 minutes. For inducing heat shock, the cells were exposed to $40^{\circ} \mathrm{C}$ for 10,15 , or 20 minutes by immersing the cultures in a shaking water bath. For cold treatment, the cultures were exposed to $4^{\circ} \mathrm{C}$ for 24 hours. Fractions of viable cells of each experiment were determined by plating appropriate dilutions of the cultures on CA agar plates before and after treatments. There were six replicates of each treatment. The controls (without IAA treatment) received the same treatments used throughout the procedure.

\section{Statistical Analysis.}

In the experiment of effect of auxin analogs and inhibitors of auxin biosynthesis or transport on 
181 algal growth, the statistical differences between different groups were analyzed with Kruskal-

182 Wallis one-way analysis of variance on ranks with post hoc Dunn's test. In the experiment of 183 plastic phenotypic changes in response to auxin analogs, the proportions of colonies with 184 different numbers of cells and mean number of cells per coenobium were compared using a one185 way analysis of variance with least significant difference post hoc test. In stress tests, the 186 significance of differences between the groups was determined using the Mann-Whitney U test. 187 A p of $<0.05$ was considered statistically significant. In these abovementioned experiments, data 188 are presented as means of three replicates \pm their standard deviations (SDs).

189

190

\section{Results}

191

Effect of Auxin Analogs and Inhibitors of Auxin Biosynthesis or Transport on Algal Growth and Phenotypic Plasticity Induction

193

194

195

196

197

198

199

200

201

202

203

204

205

206

207

208

209

210

211

212

213

214

215

216

In a previous study, we performed a dose-response analysis to determine the fitness effects of IAA on the coenobial alga D. komarekii (Chung et al., 2018). The results revealed that different concentrations of IAA had different effects on the growth and morphological changes of $D$. komarekii. Thus, we concluded that Desmodesmus can respond to the external phytohormone IAA signal and then integrate the information to initiate physiological changes. In this study, our aim was to determine whether the physiological cues of IAA-related compounds also trigger the growth and phenotypic plasticity responses in Desmodesmus. With respect to D. komarekii growth, we examined the effects of the natural auxin IAA as well as those of the synthetic auxins NAA and 2,4-D. At $300 \mu \mathrm{M}$, IAA, NAA, and 2,4-D clearly inhibited growth; however, IAA caused lower inhibition than did NAA and 2,4-D (Fig. 1a). This inhibitory effect was also observed at 100 and $200 \mu \mathrm{M}$ NAA and 2,4-D, but not in the cells treated with $100 \mu \mathrm{M}$ IAA (Fig. $1 \mathrm{~b}, \mathrm{c})$. These observations indicated that these auxin-related compounds inhibit D. komarekii growth. We next tested the effects of an auxin biosynthesis inhibitor and a polar auxin transport inhibitor. BBo strongly inhibited growth even at $100 \mu \mathrm{M}$ and its inhibitory effect increased with its concentration (Fig. 1c). At 200 and $300 \mu \mathrm{M}$, both of TIBA and BBo inhibited D. komarekii growth (Fig. 1a, b). These results suggested that inhibition of auxin transport and inhibition of YUCCA function both inhibit cell growth.

To measure phenotypic plasticity responses in algal populations, monocultures of $D$. komarekii were used. After 1 week of culturing, the monocultures of D. komarekii in the groups with exogenous $300 \mu \mathrm{M}$ IAA and synthetic auxins were compared with those in the control environment (without treatment). We found that the monocultures of D. komarekii in the control groups (without IAA treatment) were dominated by one- and four-celled coenobia (Fig. 2a-c). The morphology of $D$. komarekii monocultures changed drastically compared with the control after exposure to IAA (Fig. 2b, c). The proportion of unicells increased rapidly from day 3 , and 
217 the proportion of four-celled coenobia decreased (Fig. 2a, c). The mean number of cells per 218 particle reached its minimum on approximately day 7 (Fig. 2a), the proportion of unicells 219 increased from $37 \%$ to approximately $73 \%$, and the proportion of four-celled coenobia decreased 220 from $49 \%$ to approximately $16 \%$ on day 9 . The proportion of two-celled coenobia changed only 221 slightly from approximately $13 \%$ to approximately $7 \%$. The mean number of cells per particle in 222 the control groups remained at $>2.5$ during the 9-day period. By contrast, we found that the 223 auxin-related compounds NAA and 2,4-D both inhibited the growth of $D$. komarekii in a dose224 dependent manner, but they did not influence their number of cells per coenobium/individual 225 colony (Fig. 2d, e). In this experiment, the D. komarekii population of each culture was

226

227 228

229

230

231

232

233

234

235

236

237

238

239

240

241

242

243

244

245

246

247

248

249

250

251

252 composed of unicells and two-, four-, and eight-celled colonies; a few three-, five-, six-, and seven-celled colonies were also present, but coenobia with more than eight cells were not observed.

Through transmission electron microscopy (TEM) analysis, we confirmed that the morphological changes in coenobia were not caused by cell aggregation but by the vegetative growth of a mother cell (Fig. 3a-b). No extracellular matrix was seen on or around the cells, and the connecting strands between cells were highly visible (Fig. 3c). Electron-dense kitting material (warty layer) can be seen at each corner of coenobial junction between two neighboring cells (yellow circle; Fig. 3c). Notably, we observed that specific large unicells were formed in the monocultures of $D$. komarekii after day 5 under IAA treatment. Thus, the samples collected at day 7 after IAA treatment and the cells in the control groups were used for observation of morphology through TEM. The accumulation of many starch granules and lipid bodies was observed in the large unicells compared with the cells in control groups (Fig. 3d).

The auxin-like physiological competence of selected compounds was analyzed in Desmodesmus based on the inhibition of growth in liquid cultures and morphological changes. Thus, we performed a dose-response analysis to determine the fitness effects of IAA and other analogs on eight other Desmodesmus strains. The results revealed that different concentrations of indole derivatives had divergent effects on the growth of different Desmodesmus species (Figs. $4-5$, Supplementary Figures 1-2). In general, high concentrations $(>300 \mu \mathrm{M})$ of IAA and other analogs inhibited the growth of the algal population. Thus, Desmodesmus can respond to the external phytohormone signal of IAA and other analogs and then integrate the information to initiate physiological changes. In the subsequent experiment, our aim was to determine whether the physiological cues of IAA and other analogs in these cultures also trigger phenotypic plasticity responses.

\section{Plastic Phenotypic Changes in Response to IAA Are Strain-Dependent Behaviors}

To measure the phenotypic plasticity responses to indole derivatives, four strains of D. armatus, 
253 two strains of $D$. communis, and one strain of D. intermedius and D. opoliensis were used in this 254 study. After 1 week of treatment, the monocultures of D. armatus in the control groups (without 255 indole derivative treatment) were compared with those with indole derivatives. We found that the 256 changes in colonial morphs in D. armatus are specific to IAA but not to chemically synthesized

257

258

259

260

261

262

263

264

265

266

267

268

269

270

271

272

273

274

275

276

277

278

279

280

281

282

283

284

285

286

287

288 auxins, NAA and 2,4-D, which are chemically more stable than IAA (Figs. 4, Supplementary Figure 1). Moreover, we found the different algal strains of $D$. armatus demonstrated phenotypic plasticity to different IAA concentrations. In D. armatus JYCA037, the monocultures in the control groups were dominated by two- and four-celled coenobia, with $<2 \%$ unicells (Fig. 4a, Supplementary Figure 1). The morphology of D. armatus JYCA037 populations considerably changed under high concentration of IAA treatment compared with that in the control environment (without IAA addition). When the IAA concentration increased, the proportion of four-celled coenobia declined from $>90 \%$ to approximately $21 \%$, and the number of unicells increased from $<2 \%$ to approximately $12 \%$ and two-celled coenobia increased from approximately $7 \%$ to $66 \%$. The mean number of cells per particle of D. armatus JYCA037 decreased gradually as the IAA concentration gradually increased, and the cell number reached its minimum level at an IAA concentration of $400 \mu \mathrm{M}$ (Fig. 4a). Similar results were observed in the monocultures of D. communis JYCA040; it was dominated by two- and four-celled coenobia in the control groups (Fig. 5a, Supplementary Figure 2). When IAA concentration increased, the proportion four-celled coenobia decreased, and the number of unicells increased. The mean number of cells per coenobium particle in the control groups of these two strains remained for $>3$ days after 7-day culturing. By contrast, in D. armatus JYCA041, the monocultures in the control groups were dominated by unicells (47\%), with $47 \%$ two- and $<7 \%$ four-celled individuals (Fig. $4 \mathrm{~b}$, Supplementary Figure 1). The morphology of D. armatus JYCA041 populations changed considerably under high concentration of IAA treatment compared with that in the control environment (without IAA addition). When IAA concentration increased, the proportion of twocelled coenobia increased from approximately $47 \%$ to approximately $69 \%$ and the number of unicells declined from approximately $47 \%$ to approximately $28 \%$. The proportion of four-celled coenobia only slightly changed from approximately $6 \%$ to approximately $3 \%$. The mean number of cells per particle of $D$. armatus JYCA041 increased gradually as the IAA concentration gradually increased and reached its maximum level at an IAA concentration of $400 \mu \mathrm{M}$ (Fig. 4b, Supplementary Figure 1) Similarly, the mean number of cells per particle of D. armatus JYCA039 increased gradually as the IAA concentration gradually increased and reached its maximum level when the IAA concentration was approximately $200 \mu \mathrm{M}$ (Fig. 4d, Supplementary Figure 1). Notably, the aformentioned morphological changes were not observed in D. armatus JYCA045 even under treatment with high concentrations with IAA (Fig. 4c, Supplementary Figure 1). By contrast, we found that the auxin-related compounds NAA and 2,4- 
289 D both inhibit Desmodesmus growth in a dose-dependent manner, but the treatment did not 290 influence their number of cells of individuals in these four D. armatus strains (Fig. 4). The 291 strain-dependent response to IAA but not to NAA and 2,4-D also occurred in one strain of $D$. 292 communis (JYCA040; Fig. 5a, e, i, Supplementary Figure 2) and D. opoliensis (JYCA043; Fig. 293 5b, f, j, Supplementary Figure 2). However, the phenotypic plasticity caused by auxin analogs 294 was not obviously shown in one strain of D. communis (JYCA044; Fig. 5c, g, k, Supplementary 295 Figure 2) and D. intermedius (JYCA042; Fig. 5d, h, 1, Supplementary Figure 2).

296

297

298

299

300

301

302

303

304

305

306

307

308

309

310

311

312

313

314

315

316

317

318

319

320

321

322

323

324

\section{Effect of IAA Treatment on Stress Resistance}

In this study, we found that starch granules and lipid bodies accumulated in algal cells grown at a high IAA concentration. In this environment, algal cells also demonstrated slow growth. Thus, algae contain storage in the form of natural oils, such as neutral lipids or triglycerides, and algal growth diminishes when exposed to stresses. The data reported in Table 1 showed that IAAtreated cells could withstand sudden changes in the environment, demonstrating significantly longer survival rates in the media subjected to temperature shock $\left(40^{\circ} \mathrm{C}, 15\right.$ minutes and $4^{\circ} \mathrm{C}, 24$ hours), osmotic shock ( $0.5 \mathrm{M} \mathrm{NaCl}, 15$ and 30 minutes), oxidative stress $\left(2 \mathrm{mM} \mathrm{H}_{2} \mathrm{O}_{2}, 30\right.$

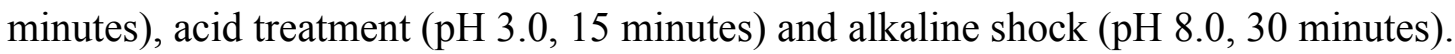

\section{Discussion}

A central question in biodiversity theory and ecology is the "paradox of the plankton," which indicates that the number of coexisting planktonic species far exceeds the expected and explicable number based on competition theory (Hutchinson, 1961). Ecologists have provided multiple solutions to the paradox by applying game theory, chaos, tradeoffs, and many other concepts in the past five decades (Tilman, 1994; Huisman \& Weissing, 1999; Károlyi et al., 2000; Kerr et al., 2002; Goyal \& Maslov, 2018). A leading theory to explain the paradox is that individual variability maintains high biodiversity in planktonic microorganisms (Menden-Deuer \& Rowlett, 2014). In aquatic ecosystems, significant evidence supports individual variability, in individual behaviors or physiology, among planktonic microorganisms. This phenotypic plasticity has played a central role in studies on the evolution of diversity. Ecologically, phenotypic plasticity has been considered particularly crucial when environmental changes occur and different phenotypes have different fitness values across environments. This plasticity decides the survival of an individual in the face of environmental changes (West-Eberhard, 1989). The plasticity even can potentiate evolvability of microorganisms by opening up new regions of the adaptive landscape (Yi \& Dean, 2016).

In our study, we revealed that the morphological characteristics of Desmodesmus changed considerably when exposed to IAA compared with the algal cells in the control environment. We 
325 found that the algal strains we assayed here have different response patterns to the external IAA.

326 In this study and our previous study, we found that when IAA concentration increased, the mean 327 number of cells per particle of some Desmodesmus species decreased (Chung et al., 2018). The 328 surface-to-volume ratios of the unicells was larger than the colony cells in microalgae. Changes 329 in colony size influence algal surface-to-volume ratios, and the surface-to-volume ratio can 330 affect light capture and nutrient uptake (Reynolds, 2006; Steele et al., 2009). Notably, in this

331

332

333

334

335

336

337

338

339

340

341

342

343

344

345

346

347

348

349

350

351

352

353

354

355

356

357

358

359

360 study, we found that in some algal strains, this trend was reversed: the mean number of cells per particle of some Desmodesmus strains was increased when IAA concentration increased. These colonial populations have higher sinking velocities than the unicells and two-celled coenobia; consequently, their competitive ability might be altered (Lürling, 2003). Thus, plasticity involving individual-level heterogeneity in behaviors and physiological characteristics is crucial for planktonic microorganisms to adapt to changing or novel conditions. This may suggest that individual variability is perhaps the key mechanism supporting planktonic biodiversity.

In this study, two widely used auxins in plant tissue culture, NAA and 2,4-D, were also used to investigate their effect on algal growth and physiological responses. These synthetic auxins show varying degrees of auxin-like activity in different bioassays (Abebie et al., 2007; SavaldiGoldstein et al., 2008). For instance, the seedlings of Arabidopsis thaliana and suspension-cultured cells of Nicotiana tabacum BY-2 were used to investigate the physiological activity of several auxin analogs, along with their capacity to induce auxin-dependent gene expression, to inhibit endocytosis and to be transported across the plasma membrane (Simon et al., 2013). The authors concluded that the major determinants for the auxin-like physiological potential of a particular compound are highly complex and involve its chemical and metabolic stability, its ability to distribute in tissues in a polar manner, and its activity toward auxinsignaling machinery. Thus, the distinct behavior of some synthetic auxin analogs suggests that they might be useful tools in investigations of the molecular mechanism of auxin action. Ohtaka et al. (2017) also examined the responses of the natural auxin (indole-3-butylic acid; IBA) as well as the synthetic auxins (NAA and 2,4-D) on the charophyte alga Klebsormidium nitens. Consistent with our results, the authors indicated that these auxin-related compounds all inhibit $K$. nitens growth in a dose-dependent manner. In their study, it was also indicated that TIBA and BBo both inhibited $K$. nitens growth. Notably, the IAA was detected in cultures of $K$. nitens, but $K$. nitens lacks the central regulators of the canonical auxin-signaling pathway found in land plants. However, the authors found that the exogenous IAA inhibited cell division and elongation, and this treatment rapidly induced expression of a LATERAL ORGAN BOUNDARIESDOMAIN transcription factor. During evolution, $K$. nitens may have acquired a primitive auxinresponse pathway to regulate transcription and cell growth. Here, we found that the natural auxin IAA and the synthetic auxins NAA and 2,4-D can all influence Desmodesmus growth rate. 
361 However, the changes in the colonial morphs in Desmodesmus are specific to IAA, but not to

362 chemically more stable synthetic auxins. These studies have suggested that structure-activity 363 relationships determined precisely at the level of a particular protein (e.g., receptor or carrier) 364 may not correspond completely to the final auxin-like physiological activity of a particular 365 compound in the streptophytes and their sister group, the chlorophytes. Thus, the comparison of 366 the structure-activity relationships for the aforementioned phenotypic changes highlights 367 differences in the structural requirements of these auxin-related physiological processes, thus

368

369

370

371

372

373

374

375

376

377

378

379

380

381

382

383

384

385

386

387

388

389

390

391

392

393

394

395

396 making the differential (or the same) phenotypic outcome of the same (or different) compound a very crucial aspect of auxin biology. However, in the use of auxin-inhibitors and other experiments derived from the Arabidopsis methodology, we should be more careful in making conclusions, because it has not been carefully tested whether the mechanisms in Arabidopsis are really the same as in the green alga. In future studies, a more comprehensive examination of auxin systems of green algae, including charophyte algae, will help elucidate the origin and evolution of the plant auxin system.

Microalgae are unicellular photosynthetic microorganisms, typically found in freshwater and marine systems. The high flexibility and adaptability of this extremely diverse group of eukaryotic organisms enable it to grow in diverse environments, including fresh water, blackish, marine, and soil environments. Microalgae coexist with heterotrophic microorganisms, and the exchange of chemical compounds is central to the interactions of microalgae with other microorganisms. How microalgal-microbial interactions and participating chemical compounds shape their communities and considerably affect their fitness remains unknown (Hom et al., 2015). Notably, not only plants but also bacteria, fungi (including yeast), and even some microalgae produce or respond to IAA (Fu et al., 2015). Researchers have hypothesized that the microbes sense environmental IAA concentrations to determine the cell density of its competitors (Spaepen et al., 2007; Fu et al., 2015; Chung et al., 2018). Thus, IAA has been speculated to be a signal that coordinates microbial behavior to enhance protection against damage by adverse conditions (Bianco et al., 2006; Chung et al., 2018). We proposed that the physiological changes in response to IAA confers a fitness advantage by promoting the ability of Desmodesmus strains to survive in their niches that often undergo fluctuations in environmental factors, such as temperature, osmotic pressure, reactive oxygen species, and $\mathrm{pH}$ changes. Under unfavorable stress conditions, such as nutritional starvation, salinity stress and high light intensity, lipid production is usually enhanced in algal cells, due to shifts in lipid biosynthetic pathways toward neutral lipid accumulation (Sun et al., 2018). Microalgae generally accumulate neutral lipids, mainly in the form of triacylglycerols (TAG) under environmental stress conditions. The accumulation of TAG likely occurs as a means of creating an energy deposit that can be readily used in response to a more favorable environment allowing for rapid growth (Tan 
397 \& Lee, 2016). In green algae, stress conditions also trigger the accumulation of starch granules in

398

399

400

401

402

403

404

405

406

407

408

409

410

411

412

413

414

415

416

417

418

419

420

421

422

423

424

425

426

427

428

429

430

431

432 the cells, with starch accumulation preceding the accumulation of lipid bodies following stress onset (Siaut et al., 2011). It is generally assumed that the starch and TAG serve as electron sinks under conditions where photosynthesis or metabolism of an exogenous carbon source remains active but the growth is limited (Hu et al., 2008). This phenomenon suggests that carbon sources in algal cells during stress conditions were allocated not only to storage lipid production but also starch biosynthesis, and this finding demonstrates the possibility of partitioning manipulation in the cells. To link physiological changes to phenotype, we performed various cell viability assays in response to heat, cold, osmotic stress, oxidative stress, reactive oxygen species, and $\mathrm{pH}$ changes. We found an increased ability to tolerate these stresses, thereby confirming the inferred enhanced stress-tolerant phenotypes when exposed to IAA. The results are consistent with earlier research on bacteria that found enhanced stress tolerance when the bacteria were pretreated with IAA across various stress conditions (Bianco et al., 2006; Imperlini et al. 2009; Donati et al., 2013). Here we verified that IAA increased the cell viability under many other stress conditions, but to varying extents for the different stresses. Understanding the mechanisms underlying the phenomenon, it is necessary to further investigate the effect of IAA treatment on some of the structural components of the envelope that may be involved in cellular response to stresses.

In natural water bodies, the importance of physical associations and biochemical interactions between microalgae and microorganisms is generally well appreciated, but the significance of these interactions to microbial ecology has not been investigated. In our previous study, we found that a low concentration of IAA promoted the growth of algal cells, but high concentrations of IAA inhibited cell growth (Chung et al., 2018). Herein, we further proved that the effects of exogenous IAA and on algal growth and phenotypic changes is species- and even strain-dependent. IAA can exert stimulatory and inhibitory effects not only on algae, fungi, and yeast but also bacteria (Prusty et al., 2004; De-Bashan et al., 2008; Hu et al., 2010; Kerkar et al. 2012; Kulkarni et al., 2013; Sun et al., 2014; Liu et al., 2016; Fu et al., 2017). Bagwell et al. (2014) reported the frequency of co-occurrence between IAA-producing bacteria and green algae in natural and engineered ecosystems and revealed that the chlorophyll content and dry weight of algal cells were IAA concentration-dependent. A recent study also indicated that IAA produced by associated bacteria was transferred to diatoms and influenced their growth in exchange for organosulfur compounds (Amin et al., 2015). Thus, exposure to IAA could be likely to affect the outcome of competition among these coexisting organisms. We finally suggested that both algae and other microorganisms altered their metabolism to defend themselves form their competitors (or suit each other's needs), and this interaction is potentially very prevalent in the aquatic ecosystems. These findings indicated that IAA is a major factor determining the competition (or mutualistic interactions) between microbial species occupying the same niche. In this study, 
433 different amounts of IAA (up to $500 \mu \mathrm{M}$ ) were used to assay the effects of exogenous IAA on 434 algal physiology. Some concerns exist that this concentration does not reflect all actual 435 concentrations found in the wild or those produced by microbes. Many studies have shown that 436 the amount of IAA that many bacteria and fungi can secrete was similar to or even more than $437500 \mu \mathrm{M}$ which is the highest dose we used here (Mohite, 2013; Limtong et al., 2014; Nutaratat et 438 al., 2015, 2017). According to our previous study, some fungi (e.g. Aureobasidium pullulans) 439 can even can secrete more than $200 \mu \mathrm{g} / \mathrm{mL}$ IAA $(\sim 1000 \mu \mathrm{M})(\mathrm{Fu}$ et al., 2016). Furthermore, the 440 IAA measured in this study was secreted by microbes into liquid medium. We believe that the 441 amount of IAA produced by these microbes in the microniche under wild conditions should be 442 higher than that we used in this study.

443

444 Conclusions

445 In this study, we indicated that the changes in colonial morphs of five species of the green alga 446 Desmodesmus were specific to IAA but not to the chemically more stable synthetic auxins, 447 naphthalene-1-acetic acid and 2,4-dichlorophenoxyacetic acid. Our results also proved that IAA 448 treatment potentially increases the tolerance of Desmodesmus algae to several stress conditions. 449 Our results suggest that IAA could be used as a diffusible signal to elicit interspecific 450 communication among different organisms. Furthermore, the plasticity involving individual451 level heterogeneity in behaviors and physiological characteristics is crucial for planktonic 452 microorganisms to adapt to changing or novel conditions.

453

454 Acknowledgments We thank the members of the Chou Laboratory for their helpful discussions 455 and comments on the manuscript. We are grateful to the staff of the Electron Microscopy 456 Laboratory, Tzu Chi University, for technical support. This manuscript was edited by Wallace 457 Academic Editing. This work was supported by grants from the Ministry of Science and 458 Technology (MOST 105-2311-B-018-001-MY3 and MOST 108-2621-B-018-002-MY3 to Jui$459 \mathrm{Yu} \mathrm{Chou})$. 
462 References

463 Abebie B, Lers A, Philosoph-Hadas S, Goren R, Riov J, Meir S. 2007. Differential effects of

464

465

466

467

468

469

470

471

472

473

474

475

476

477

478

479

480

481

482

483

484

485

486

487

488

489

490

491

492

493

494

495

496

497

NAA and 2, 4-D in reducing floret abscission in Cestrum (Cestrum elegans) cut flowers are associated with their differential activation of Aux/IAA homologous genes. Annals of Botany 101:249-259.

Amin S, Hmelo L, Van Tol H, Durham B, Carlson L, Heal K, Morales R, Berthiaume C, Parker M, Djunaedi B. 2015. Interaction and signalling between a cosmopolitan phytoplankton and associated bacteria. Nature 522:98.

Bagwell CE, Piskorska M, Soule T, Petelos A, Yeager CM. 2014. A diverse assemblage of indole-3-acetic acid producing bacteria associate with unicellular green algae. Applied Biochemistry and Biotechnology 173:1977-1984.

Bianco C, Imperlini E, Calogero R, Senatore B, Amoresano A, Carpentieri A, Pucci P, Defez R. 2006. Indole-3-acetic acid improves Escherichia coli's defences to stress. Archives of Microbiology 185:373-382. Chung TY, Kuo CY, Lin WJ, Wang WL, Chou JY. 2018. Indole-3-acetic-acid-induced phenotypic plasticity in Desmodesmus algae. Scientific Reports 8:10270.

De-Bashan LE, Antoun H, Bashan Y. 2008. Involvement of indole-3-acetic acid produced by the growth-promoting bacterium Azospirillum spp. In promoting growth of Chlorella vulgaris. Journal of Phycology 44:938-947.

Dhonukshe P, Grigoriev I, Fischer R, Tominaga M, Robinson DG, Hašek J, Paciorek T, Petrášek J, Seifertová D, Tejos R. 2008. Auxin transport inhibitors impair vesicle motility and actin cytoskeleton dynamics in diverse eukaryotes. Proceedings of the National Academy of Sciences 105:4489-4494.

Donati AJ, Lee HI, Leveau JH, Chang WS. 2013. Effects of indole-3-acetic acid on the transcriptional activities and stress tolerance of Bradyrhizobium japonicum. PLOS ONE 8:e76559.

Fu SF, Chen HW, Wei JY, Lee YI, Chou J-Y. 2017. Yeast-produced IAA is not only involved in the competition among yeasts but also promotes plant growth and development. Nova Hedwigia 105:135-150.

Fu SF, Sun PF, Lu HY, Wei JY, Xiao HS, Fang WT, Cheng BY, Chou JY. 2016. Plant growthpromoting traits of yeasts isolated from the phyllosphere and rhizosphere of Drosera spatulata Lab. Fungal Biology 120:433-448.

Fu SF, Wei JY, Chen HW, Liu YY, Lu HY, Chou JY. 2015. Indole-3-acetic acid: A widespread physiological code in interactions of fungi with other organisms. Plant Signaling \& Behavior 10:e1048052.

Goyal A, Maslov S. 2018. Diversity, stability, and reproducibility in stochastically assembled

Peer) reviewing PDF | (2019:10:42400:2:0:NEW 14 Jan 2020) 
498

499

500

501

502

503

504

505

506

507

508

509

510

511

512

513

514

515

516

517

518

519

520

521

522

523

524

525

526

527

528

529

530

531

532

533

microbial ecosystems. Physical Review Letters 120:158102.

Hessen DO, Van Donk E. 1993. Morphological changes in Scenedesmus induced by substances released from Daphnia. Archiv für Hydrobiologie 127:129-129.

Hom EF, Aiyar P, Schaeme D, Mittag M, Sasso S. 2015. A chemical perspective on microalgalmicrobial interactions. Trends in Plant Science 20:689-693.

$\mathrm{Hu}$ M, Zhang C, Mu Y, Shen Q, Feng Y. 2010. Indole affects biofilm formation in bacteria. Indian Journal of Microbiology 50:362-368.

$\mathrm{Hu}$ Q, Sommerfeld M, Jarvis E, Ghirardi M, Posewitz M, Seibert M, Darzins A. 2008. Microalgal triacylglycerols as feedstocks for biofuel production: perspectives and advances. The Plant Journal 54:621-639.

Huisman J, Weissing FJ. 1999. Biodiversity of plankton by species oscillations and chaos. Nature 402:407.

Hutchinson GE. 1961. The paradox of the plankton. The American Naturalist 95:137-145.

Imperlini E, Bianco C, Lonardo E, Camerini S, Cermola M, Moschetti G, Defez R. 2009. Effects of indole-3-acetic acid on Sinorhizobium meliloti survival and on symbiotic nitrogen fixation and stem dry weight production. Appl Microbiol Biotechnol 83:727-738.Jusoh M, Loh SH, Chuah TS, Aziz A, Cha TS. 2015. Indole-3-acetic acid (IAA) induced changes in oil content, fatty acid profiles and expression of four fatty acid biosynthetic genes in Chlorella vulgaris at early stationary growth phase. Phytochemistry 111:65-71.

Kakei Y, Yamazaki C, Suzuki M, Nakamura A, Sato A, Ishida Y, Kikuchi R, Higashi S, Kokudo Y, Ishii T. 2015. Small-molecule auxin inhibitors that target YUCCA are powerful tools for studying auxin function. The Plant Journal 84:827-837.

Kerkar S, Raiker L, Tiwari A, Mayilraj S, Dastager S. 2012. Biofilm-associated indole acetic acid producing bacteria and their impact in the proliferation of biofilm mats in solar salterns. Biologia 67:454-460.

Kerr B, Riley MA, Feldman MW, Bohannan BJ. 2002. Local dispersal promotes biodiversity in a real-life game of rock-paper-scissors. Nature 418:171.

Károlyi G, Péntek Á, Scheuring I, Tél T, Toroczkai Z. 2000. Chaotic flow: the physics of species coexistence. Proceedings of the National Academy of Sciences 97:13661-13665.

Kulkarni GB, Sanjeevkumar S, Kirankumar B, Santoshkumar M, Karegoudar T. 2013. Indole-3acetic acid biosynthesis in Fusarium delphinoides strain GPK, a causal agent of Wilt in Chickpea. Applied Biochemistry and Biotechnology 169:1292-1305.

Limtong S, Kaewwichian R, Yongmanitchai W, Kawasaki H. 2014. Diversity of culturable yeasts in phylloplane of sugarcane in Thailand and their capability to produce indole-3acetic acid. World Journal of Microbiology and Biotechnology 30:1785-1796.

Lürling M. 2003. Phenotypic plasticity in the green algae Desmodesmus and Scenedesmus with 
534

535

536

537

538

539

540

541

542

543

544

545

546

547

548

549

550

551

552

553

554

555

556

557

558

559

560

561

562

563

564

565

566

567

568

569

special reference to the induction of defensive morphology. Annales de Limnologie International Journal of Limnology 39:85-101.

Lürling M, Van Donk E. 1996. Zooplankton-induced unicell-colony transformation in Scenedesmus acutus and its effect on growth of herbivore Daphnia. Oecologia 108:432437.

Lürling M, Van Donk E. 2000. Grazer-induced colony formation in Scenedesmus: are there costs to being colonial? Oikos 88:111-118.

Liu YY, Chen HW, Chou JY. 2016. Variation in indole-3-acetic acid production by wild Saccharomyces cerevisiae and $S$. paradoxus strains from diverse ecological sources and its effect on growth. PLOS ONE 11:e0160524.

Mazur H, Konop A, Synak R. 2001. Indole-3-acetic acid in the culture medium of two axenic green microalgae. Journal of Applied Phycology 13:35-42.

Menden-Deuer S, Rowlett J. 2014. Many ways to stay in the game: individual variability maintains high biodiversity in planktonic microorganisms. Journal of The Royal Society Interface 11:20140031.

Mohite B. 2013. Isolation and characterization of indole acetic acid (IAA) producing bacteria from rhizospheric soil and its effect on plant growth. Journal of Soil Science and Plant Nutrition 13: 638-649.

Nutaratat P, Amsri W, Srisuk N, Arunrattiyakorn P, Limtong S. 2015. Indole-3-acetic acid production by newly isolated red yeast Rhodosporidium paludigenum. The Journal of General and Applied Microbiology 61:1-9.

Nutaratat P, Monprasit A, Srisuk N. 2017. High-yield production of indole-3-acetic acid by Enterobacter sp. DMKU-RP206, a rice phyllosphere bacterium that possesses plant growth-promoting traits. 3 Biotech 7:305.

Natrah FM, Bossier P, Sorgeloos P, Yusoff FM, Defoirdt T. 2014. Significance of microalgalbacterial interactions for aquaculture. Reviews in Aquaculture 6:48-61.

Neustupa J, Hodac L. 2005. Changes in shape of the coenobial cells of an experimental strain of Pediastrum duplex var. duplex (Chlorophyta) reared at different pHs. Preslia 77:439-452.

Ohtaka K, Hori K, Kanno Y, Seo M, Ohta H. 2017. Primitive auxin response without TIR1 and Aux/IAA in the charophyte alga Klebsormidium nitens. Plant Physiology 174:1621-1632.

Pan YY, Wang ST, Chuang LT, Chang YW, Chen CN. 2011. Isolation of thermo-tolerant and high lipid content green microalgae: oil accumulation is predominantly controlled by photosystem efficiency during stress treatments in Desmodesmus. Bioresource technology 102:10510-10517.

Pena-Castro JM, Martinez-Jeronimo F, Esparza-Garcia F, Canizares-Villanueva RO. 2004. Phenotypic plasticity in Scenedesmus incrassatulus (Chlorophyceae) in response to heavy 
$570 \quad$ metals stress. Chemosphere 57:1629-1636.

571 Piotrowska-Niczyporuk A, Bajguz A. 2014. The effect of natural and synthetic auxins on the 572 growth, metabolite content and antioxidant response of green alga Chlorella vulgaris 573 (Trebouxiophyceae). Plant Growth Regulation 73:57-66.

574 Prieto C, Rosa E, Cordoba C, Nancy M, Montenegro J, Andres M, González-Mariño GE. 2011. 575 Production of indole-3-acetic acid in the culture medium of microalga Scenedesmus 576 obliquus (UTEX 393). Journal of the Brazilian Chemical Society 22:2355-2361.

577 Prusty R, Grisafi P, Fink GR. 2004. The plant hormone indoleacetic acid induces invasive 578 growth in Saccharomyces cerevisiae. Proceedings of the National Academy of Sciences $579 \quad 101: 4153-4157$.

580 Qian H, Chen W, Li J, Wang J, Zhou Z, Liu W, Fu Z. 2009. The effect of exogenous nitric oxide 581 on alleviating herbicide damage in Chlorella vulgaris. Aquatic Toxicology 92:250-257.

582 Reynolds CS. 2006. The ecology of phytoplankton: Cambridge University Press.

583 Savaldi-Goldstein S, Baiga TJ, Pojer F, Dabi T, Butterfield C, Parry G, Santner A, Dharmasiri N, 584 Tao Y, Estelle M. 2008. New auxin analogs with growth-promoting effects in intact 585 586 plants reveal a chemical strategy to improve hormone delivery. Proceedings of the National Academy of Sciences 105:15190-15195.

Siaut M, Cuiné S, Cagnon C, Fessler B, Nguyen M, Carrier P, Beyly A, Beisson F, Triantaphylidès C, Li-Beisson Y. 2011. Oil accumulation in the model green alga Chlamydomonas reinhardtii: characterization, variability between common laboratory strains and relationship with starch reserves. BMC Biotechnology 11:7.

Simon S, Kubeš M, Baster P, Robert S, Dobrev PI, Friml J, Petrášek J, Zažímalová E. 2013. Defining the selectivity of processes along the auxin response chain: a study using auxin analogues. New Phytologist 200:1034-1048.

Spaepen S, Vanderleyden J, Remans R. 2007. Indole-3-acetic acid in microbial and microorganism-plant signaling. FEMS Microbiology Reviews 31:425-448.

Steele JH, Thorpe SA, Turekian KK. 2009. Elements of physical oceanography: a derivative of the encyclopedia of ocean sciences: Academic Press.

Sun PF, Fang WT, Shin LY, Wei JY, Fu SF, Chou JY. 2014. Indole-3-acetic acid-producing yeasts in the phyllosphere of the carnivorous plant Drosera indica L. PLOS ONE 9:e114196.

Sun XM, Ren LJ, Zhao QY, Ji XJ, Huang H. 2018. Microalgae for the production of lipid and carotenoids: a review with focus on stress regulation and adaptation. Biotechnol Biofuels $11: 272$.

Tan KWM, Lee YK. 2016. The dilemma for lipid productivity in green microalgae: importance of substrate provision in improving oil yield without sacrificing growth. Biotechnology 
$606 \quad$ for Biofuels 9:255.

607 Tilman D. 1994. Competition and biodiversity in spatially structured habitats. Ecology 75:2-16.

608 West-Eberhard MJ. 1989. Phenotypic plasticity and the origins of diversity. Annual Review of 609 Ecology, Evolution, and Systematics 20:249-278.

$610 \mathrm{Wu}$ X, Zhang J, Qin B, Cui G, Yang Z. 2013. Grazer density-dependent response of induced 611 colony formation of Scenedesmus obliquus to grazing-associated infochemicals. $612 \quad$ Biochemical Systematics and Ecology 50:286-292.

613 Yi X, Dean AM. 2016. Phenotypic plasticity as an adaptation to a functional trade-off. eLife $614 \quad$ 5:e19307.

615 


\section{Figure legends}

618 Fig. 1 Growth of coenobial algae Desmodesmus komarekii in the presence of several auxins and 619 inhibitors of auxin biosynthesis and auxin transport. D. komarekii was cultured in the presence of 620 a 300, b 200, and c $100 \mu \mathrm{M}$ auxin derivatives, including indole-3-acetic acid (IAA), 2,4621 dichlorophenoxyacetic acid (2,4-D), naphthalene-1-acetic acid (NAA), a polar auxin transport 622 inhibitor, 2,3,5-triiodobenzoic acid (TIBA), and a potent YUCCA enzyme inhibitor and 623 Arabidopsis growth inhibitor, 4-biphenylboronic acid (BBo). Growth curves of D. komarekii for 624 each compound were measured at 1, 3, 5, 7 and 9 days. Error bars represent standard deviation of 625 values for three replicates. Data were evaluated with Kruskal-Wallis one-way analysis of 626 variance on ranks with post hoc Dunn's test. Different lower case letters indicate significant 627 differences $(\mathrm{p}<0.05)$.

628

629 Fig. 2 The monocultures of Desmodesmus komarekii in the groups with exogenous IAA and 630 synthetic auxins were compared with those in the control environment (without treatment). a 631 Mean number of cells per coenobium of Desmodesmus komarekii cultured at $300 \mu \mathrm{M}$ indole-3632 acetic acid (IAA), 2,4-dichlorophenoxyacetic acid (2,4-D), and naphthalene-1-acetic acid (NAA) 633 concentrations and cells without treatment. Data are presented as means $(\mathrm{n}=3)$ for each group, 634 and morphotype percentages and cell types were based on 200 cell counts in each repeat. Means 635 with the same letter are not significantly different from each other according to a one-way 636 analysis of variance and least significant difference post hoc test. Different lower case letters 637 indicate significant differences $(\mathrm{p}<0.05)$. b-e The proportions of unicells and of two- and four638 celled coenobia of Desmodesmus komarekii cultured at $300 \mu \mathrm{M}$ IAA, 2,4-D, and NAA 639 concentrations and cells without treatment.

640

641 Fig. 3 Transmission electron micrographs of Desmodesmus komarekii cells under indole-3-acetic 642 acid (IAA) treatment. a-b Through transmission electron microscopy, we confirmed that the 643 morphological changes in coenobia were not caused by cell aggregation but by the vegetative 644 growth of a mother cell. c No extracellular matrix was seen on or around the cells, and the 645 connecting strands between cells were highly visible. Electron-dense kitting material (warty 646 layer) can be seen at each corner of coenobial junction between two neighboring cells (yellow 647 circle). d The accumulation of many starch granules (S) and lipid bodies (L) was observed in the 648 large unicells at day 7 after IAA treatment compared with the cells in control groups.

649

650 Fig. 4 Mean number of cells per coenobium in three strains of Desmodesmus armatus cultured at 651 different indole-3-acetic acid (IAA), 2,4-dichlorophenoxyacetic acid (2,4-D), and naphthalene-1acetic acid (NAA) concentrations. Data are presented as means $(n=3)$ for each group, and 
653 morphotype percentages and cell types were based on 200 cell counts in each repeat. Means with 654 the same letter are not significantly different from each other according to the results of a one655 way analysis of variance and least significant difference post hoc test. a, e, i D. armatus 656 JYCA037. b, f, j D. armatus JYCA041. c, g, k D. armatus JYCA045. d, h, l D. armatus 657 JYCA039. Data were evaluated with a one-way analysis of variance with least significant 658 difference post hoc test. Different lower case letters indicate significant differences $(\mathrm{p}<0.05)$.

659

660 Fig. 5 Mean number of cells per coenobium of different Desmodesmus strains cultured at 661 different indole-3-acetic acid (IAA), 2,4-dichlorophenoxyacetic acid (2,4-D), and naphthalene-1662 acetic acid (NAA) concentrations. Data are presented as means $(n=3)$ for each group, and 663 morphotype percentages and cell types were based on 200 cell counts in each repeat. Means with 664 the same letter are not significantly different from each other according to a one-way analysis of 665 variance and least significant difference post hoc test. a, e, i D. communis JYCA040. b, f, j D. 666 opoliensis JYCA043. c, g, k D. communis JYCA044. d, h, l D. intermedius JYCA042. Data were 667 evaluated with a one-way analysis of variance with least significant difference post hoc test. 668 Different lower case letters indicate significant differences $(\mathrm{p}<0.05)$.

669

670 


\section{Figure 1}

Figure 1

Fig. 1 Growth of coenobial algae Desmodesmus komarekii in the presence of several auxins and inhibitor of auxin biosynthesis and auxin transport. D. komarekii was cultured in the presence of a 300, b 200, and c $100 \mu \mathrm{M}$ auxin derivatives, including indole-3-acetic acid (IAA), 2,4-dichlorophenoxyacetic acid (2,4-D), naphthalene-1-acetic acid (NAA), a polar auxin transport inhibitor, 2,3,5-triiodobenzoic acid (TIBA), or a potent YUCCA enzyme inhibitor and Arabidopsis growth inhibitor, 4-biphenylboronic acid (BBo). Growth curves of $D$. komarekii for each compound were measured at 1, 3, 5, 7 and 9 days. Error bars represent standard deviation of values for three replicates. Data were evaluated with Kruskal-Wallis one-way analysis of variance on ranks with post hoc Dunn's test. Different lower case letters indicate significant differences $(p<0.05)$ 
(a)

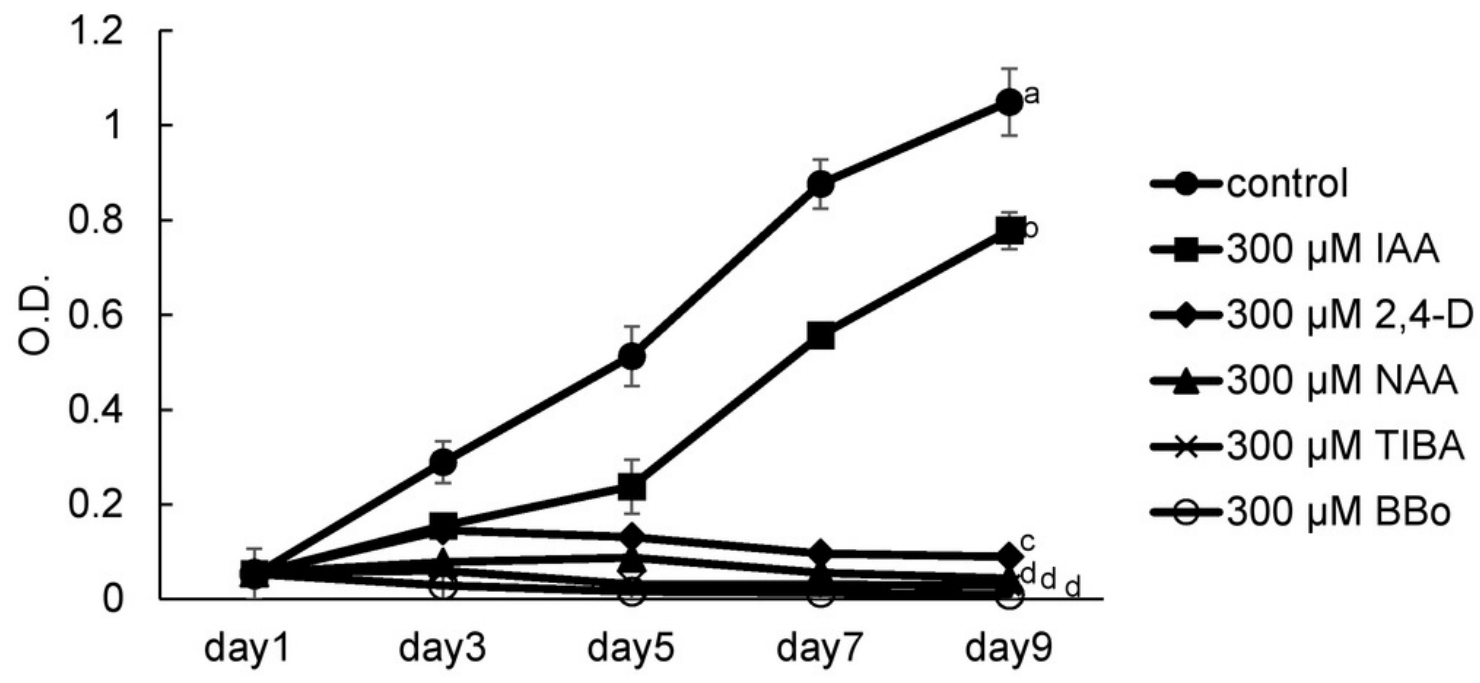

(b)
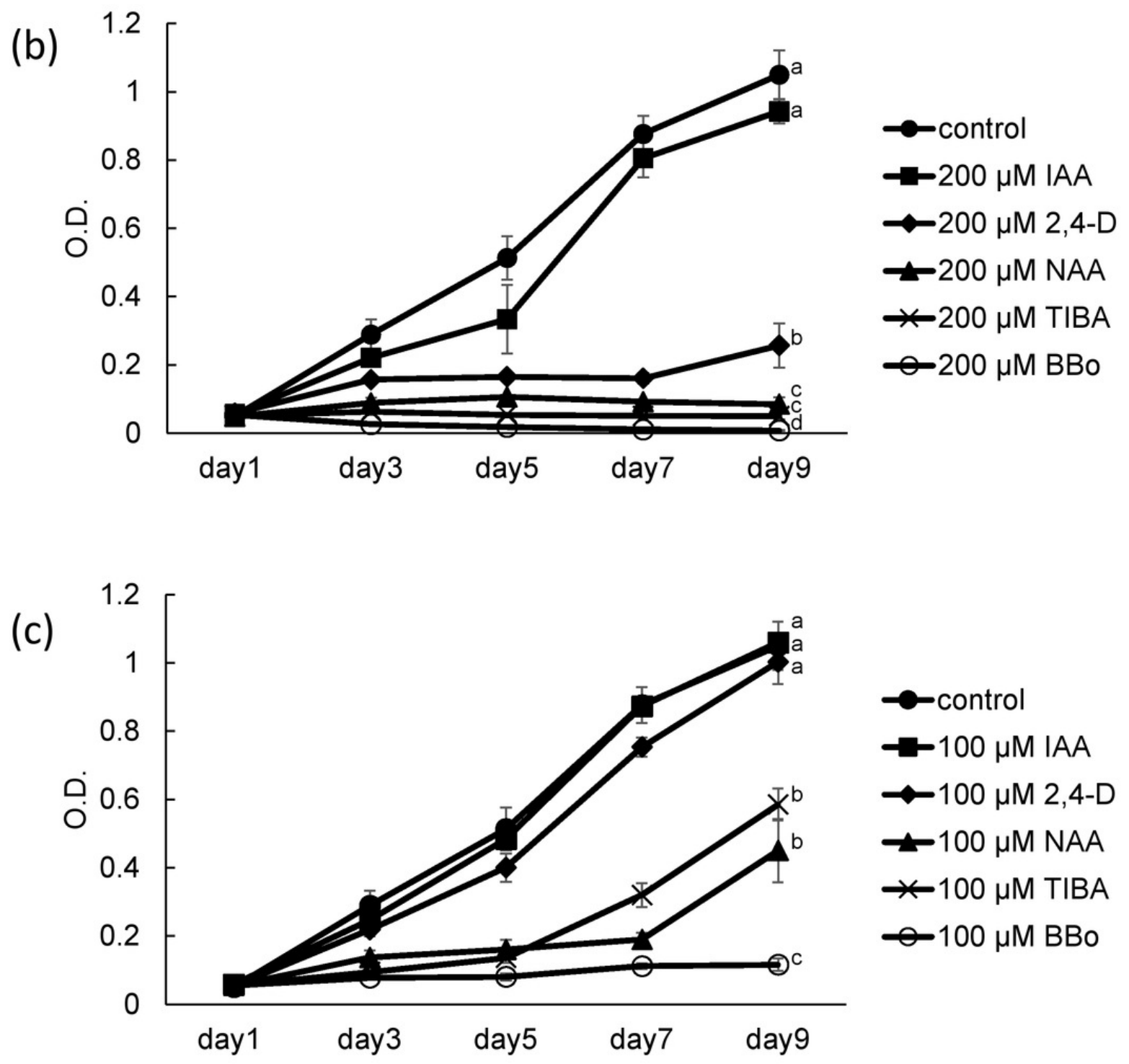

-control

$-100 \mu \mathrm{M}$ IAA

$\sim 100 \mu \mathrm{M} 2,4-\mathrm{D}$

$-100 \mu \mathrm{M} N A A$

$* 100 \mu \mathrm{M}$ TIBA

$\multimap 100 \mu \mathrm{M}$ BBo 


\section{Figure 2}

Figure 2

Fig. 2 Mean number of cells per coenobium and proportions of unicells and of two- and fourcelled coenobia of Desmodesmus komarekii cultured at $300 \mu \mathrm{M}$ indole-3-acetic acid (IAA), 2,4-dichlorophenoxyacetic acid (2,4-D), and naphthalene-1-acetic acid (NAA) concentrations and cells without treatment. Data are presented as means $(n=3)$ for each group, and morphotype percentages and cell types were based on 200 cell counts in each repeat. Means with the same letter are not significantly different from each other according to a one-way analysis of variance and least significant difference post hoc test. 


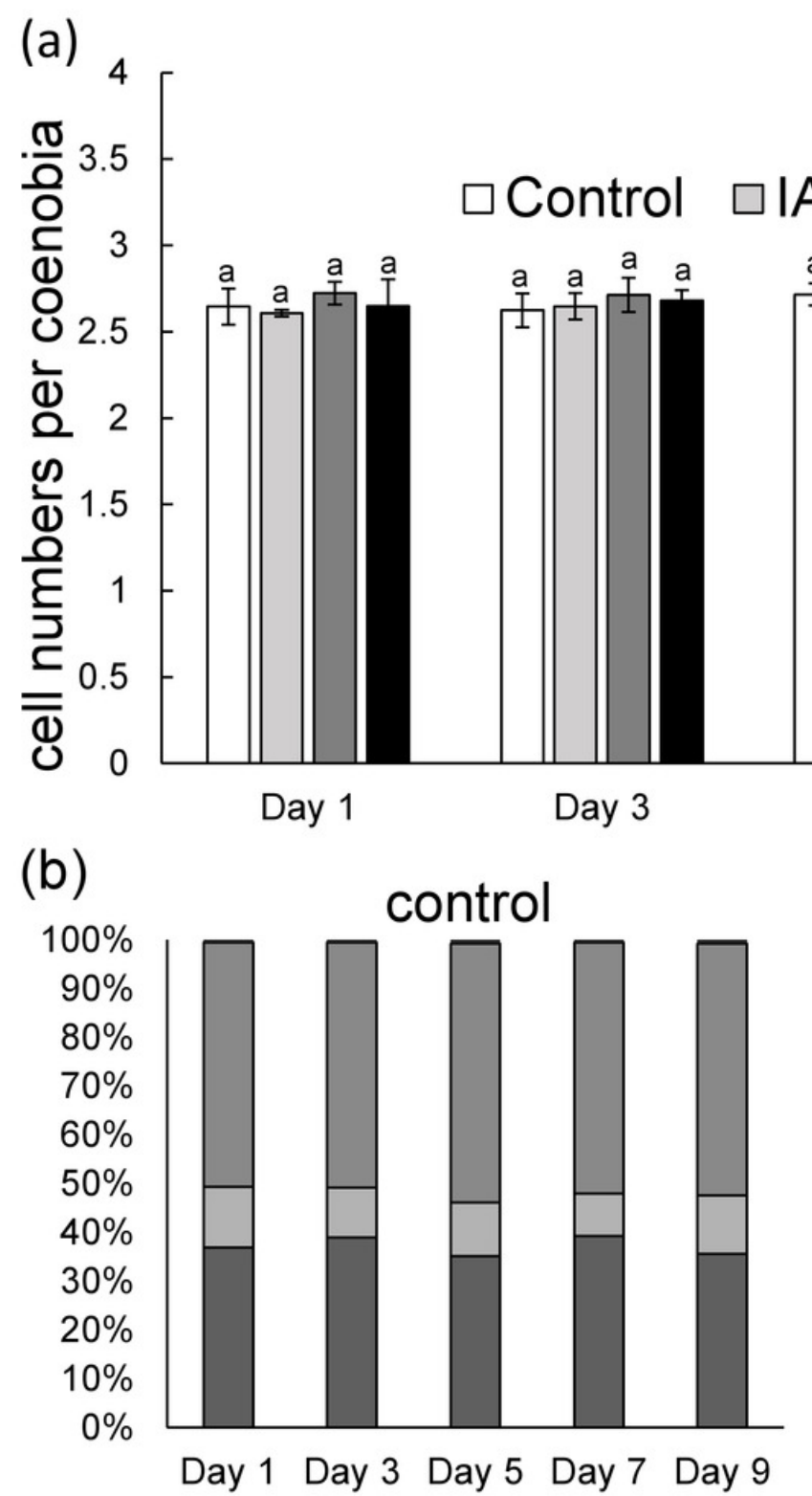

(d)

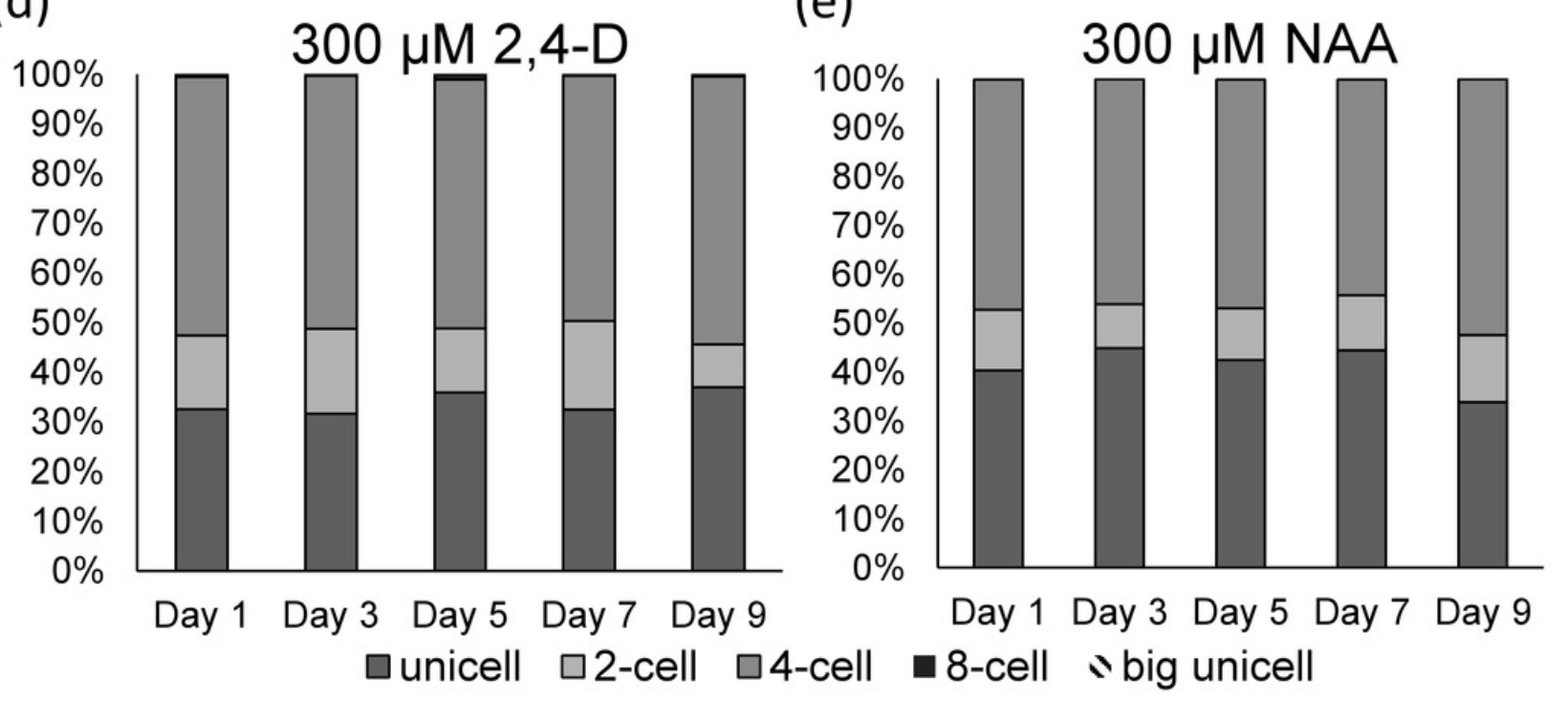




\section{Figure 3}

Figure 3

Fig. 3 Transmission electron micrographs of Desmodesmus komarekii cells under indole-3acetic acid (IAA) treatment. a-b Through transmission electron microscopy, we confirmed that the morphological changes in coenobia were not caused by cell aggregation but by the vegetative growth of a mother cell. c No extracellular matrix was seen on or around the cells, and the connecting strands between cells were highly visible. Electron-dense kitting material (warty layer) can be seen at each corner of coenobial junction between two neighboring cells (yellow circle). d The accumulation of many starch granules (S) and lipid bodies (L) was observed in the large unicells at day 7 after IAA treatment compared with the cells in control groups. 

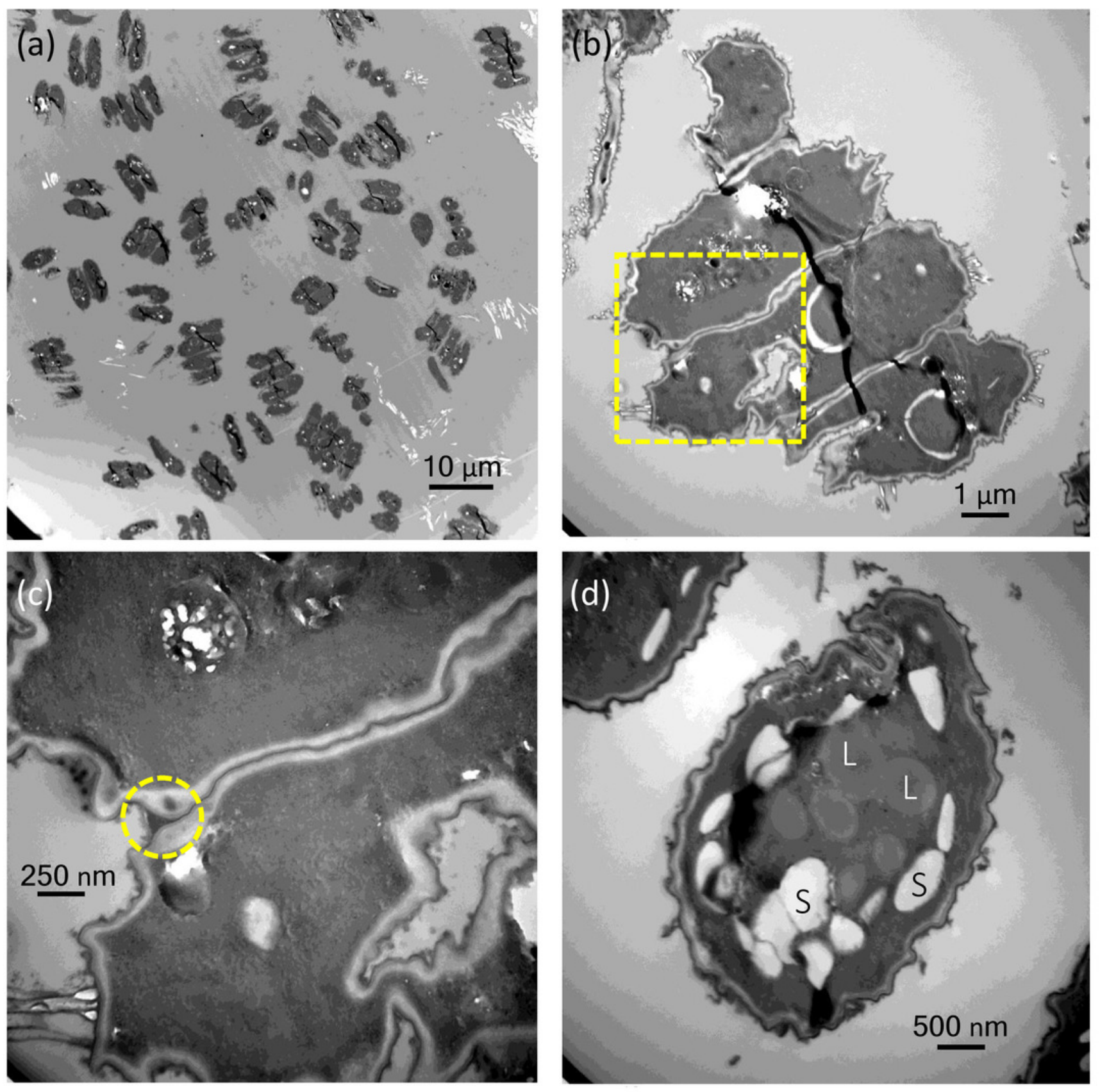


\section{Figure 4}

Figure 4

Fig. 4 Mean number of cells per coenobium in three strains of Desmodesmus armatus cultured at different indole-3-acetic acid (IAA), 2,4-dichlorophenoxyacetic acid (2,4-D), and naphthalene-1-acetic acid (NAA) concentrations. Data are presented as means ( $n=3)$ for each group, and morphotype percentages and cell types were based on 200 cell counts in each repeat. Means with the same letter are not significantly different from each other according to the results of a one-way analysis of variance and least significant difference post hoc test. a, e, i $D$. armatus JYCA037. b, $\mathbf{f}, \mathbf{j} D$. armatus JYCA041. $\mathbf{c}, \mathbf{g}, \mathbf{k} D$. armatus JYCA045. d, h, I D. armatus JYCA039. Data were evaluated with a one-way analysis of variance with least significant difference post hoc test. Different lower case letters indicate significant differences $(p<0.05)$. 

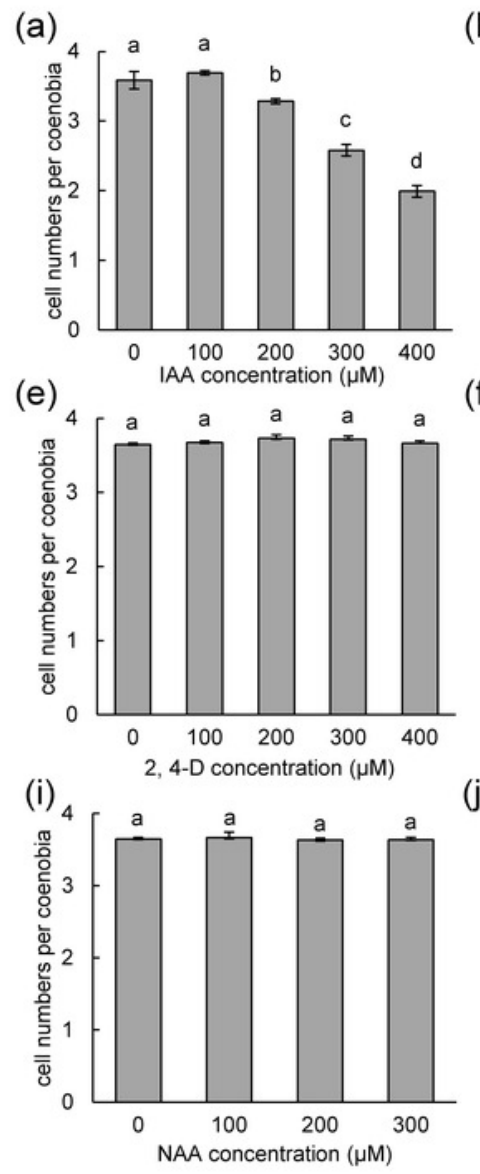

(b)

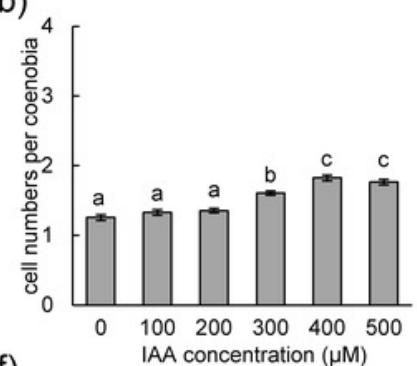

(f)

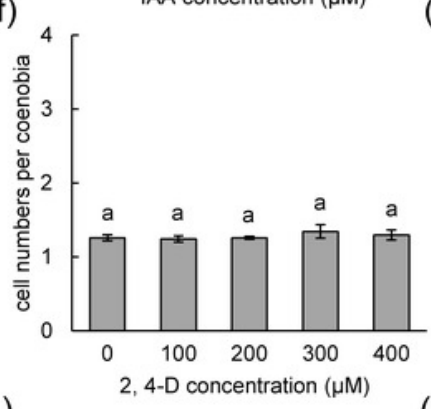

(j)

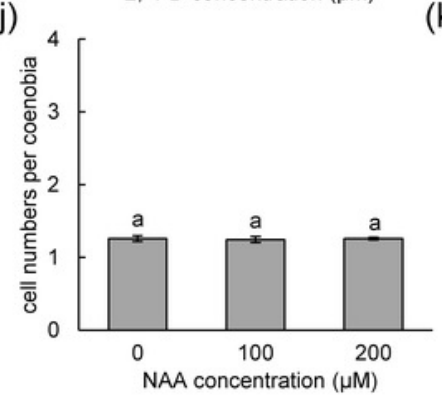

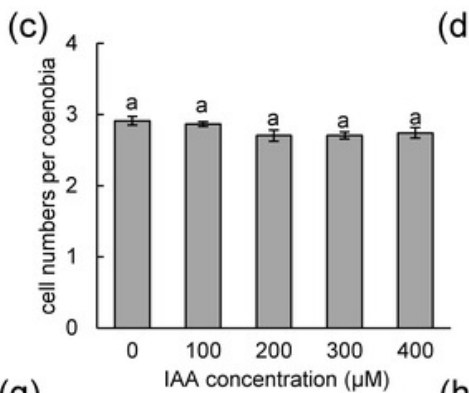

(d)
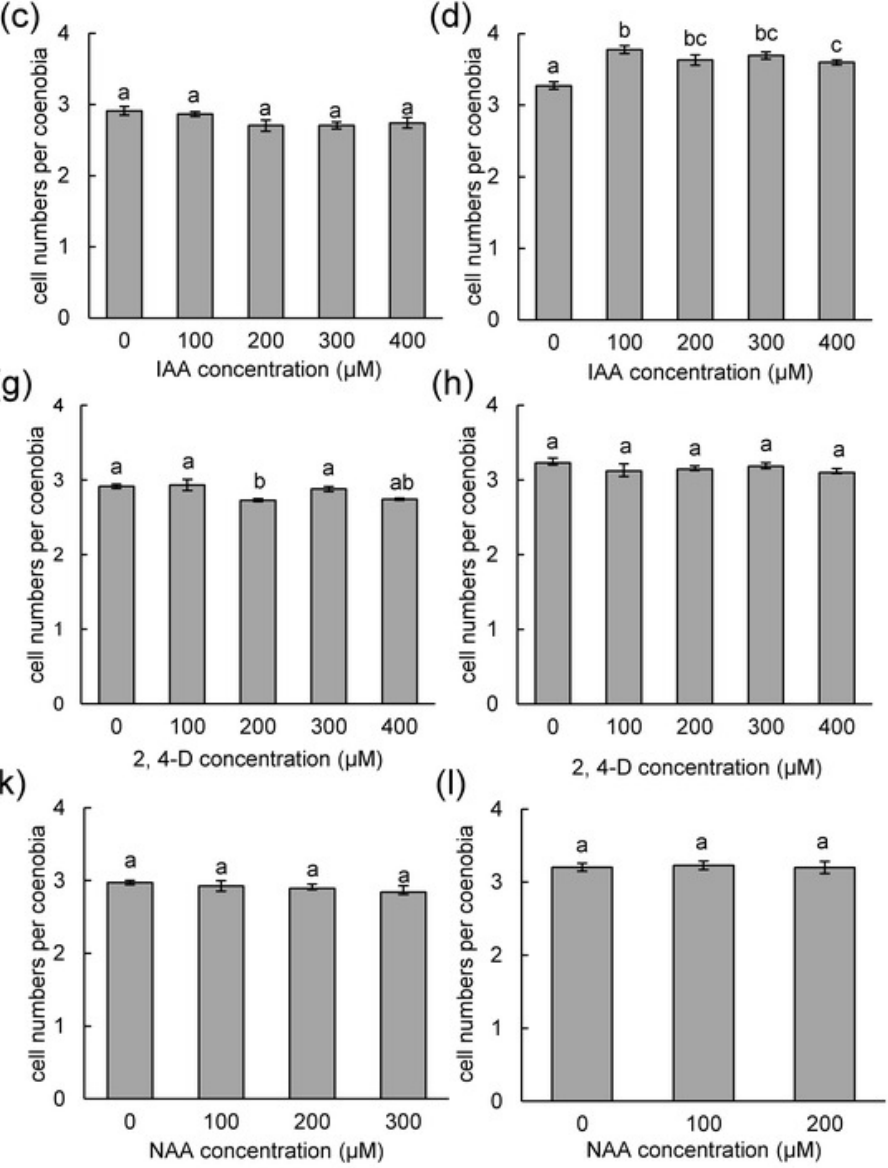

(I) 2, 4-D concentration $(\mu \mathrm{M})$

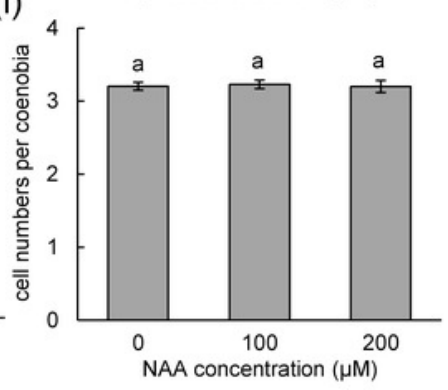




\section{Figure 5}

Figure 5

Fig. 5 Mean number of cells per coenobium of different Desmodesmus strains cultured at different indole-3-acetic acid (IAA), 2,4-dichlorophenoxyacetic acid (2,4-D), and naphthalene-1-acetic acid (NAA) concentrations. Data are presented as means $(n=3)$ for each group, and morphotype percentages and cell types were based on 200 cell counts in each repeat. Means with the same letter are not significantly different from each other according to a one-way analysis of variance and least significant difference post hoc test. a, e, i $D$. communis JYCA040. $\mathbf{b}, \mathbf{f}, \mathbf{j} D$. opoliensis JYCA043. $\mathbf{c}, \mathbf{g}, \mathbf{k} D$. communis JYCA044. $\mathbf{d}, \mathbf{h}$, I $D$. intermedius JYCA042. Data were evaluated with a one-way analysis of variance with least significant difference post hoc test. Different lower case letters indicate significant differences $(p<0.05)$. 
(a)

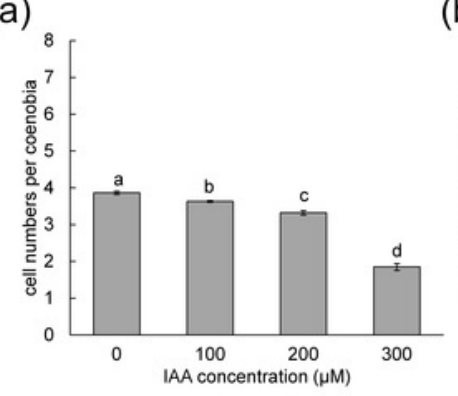

(e)
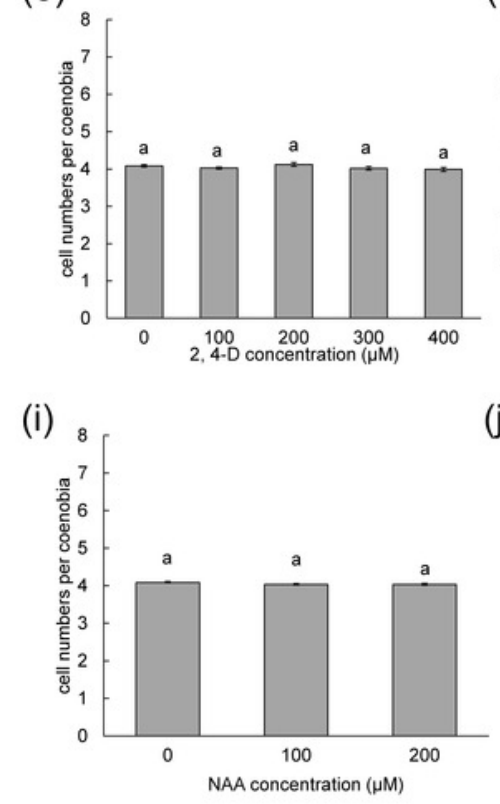

(b)

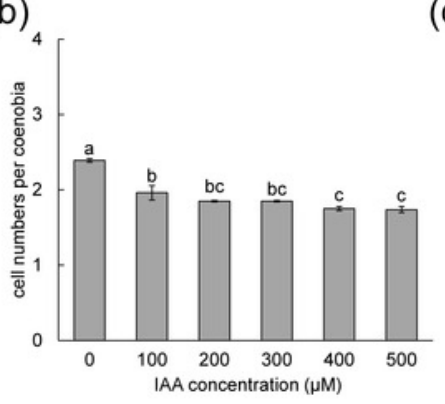

(f)
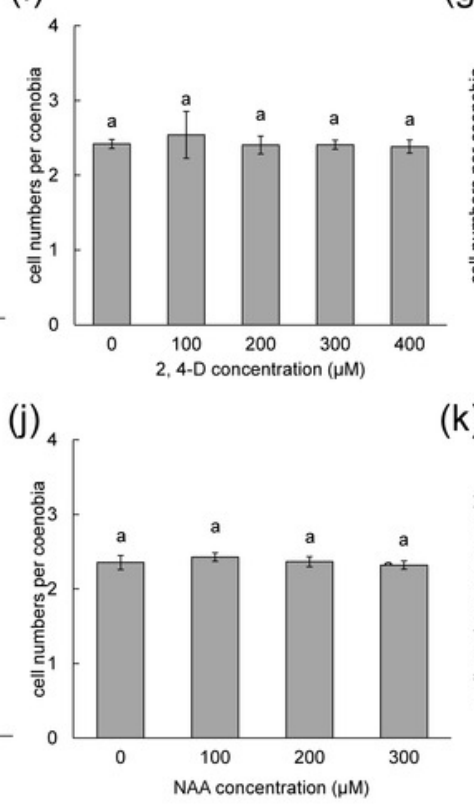

(c)

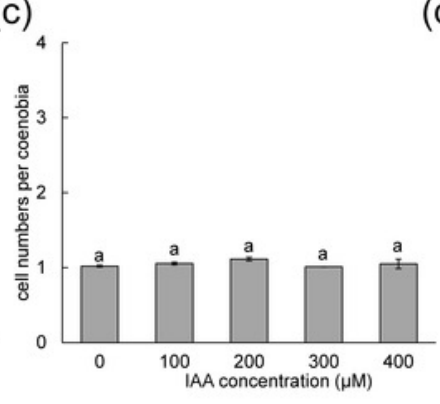

(g)

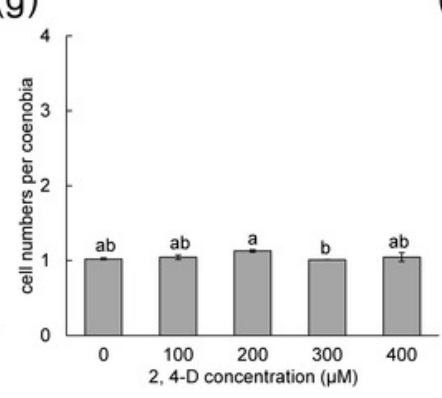

(k)

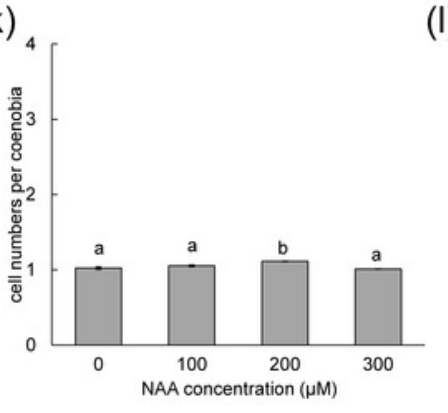

(d)

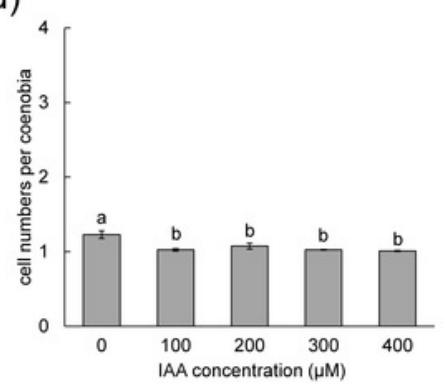

(h)

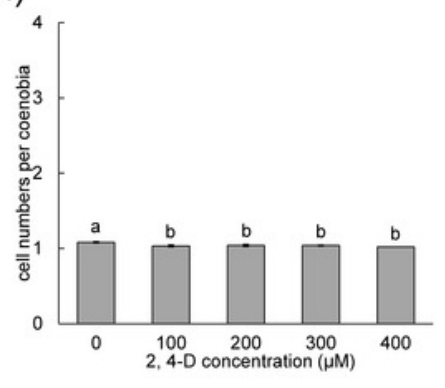

(l)

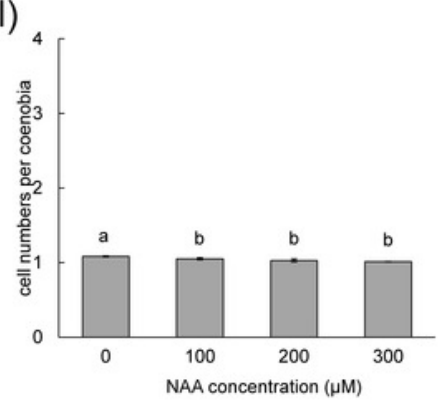




\section{Table 1 (on next page)}

Table 1

Table 1 Increased resistance of $D$. komarekii cells to various stress conditions after exposure to IAA 
1 Table 1 Increased resistance of D. komarekii cells to various stress conditions after exposure to 2 IAA

\begin{tabular}{lll}
\hline & \multicolumn{2}{c}{ Curvival (\%) } \\
& \multicolumn{1}{c}{ Control } & \multicolumn{1}{c}{ IAA-treated } \\
\hline Heat-shock $\left(40^{\circ} \mathrm{C}, 10 \mathrm{mins}\right)$ & $76.0 \pm 15.4$ & $87.3 \pm 9.9$ \\
Heat-shock $\left(40^{\circ} \mathrm{C}, 15 \mathrm{mins}\right)$ & $66.6 \pm 9.3$ & $85.4 \pm 3.5^{* *}$ \\
Heat-shock $\left(40^{\circ} \mathrm{C}, 20 \mathrm{mins}\right)$ & $52.8 \pm 15.8$ & $62.0 \pm 19.3$ \\
Cold-shock $\left(4^{\circ} \mathrm{C}, 24 \mathrm{hrs}\right)$ & $24.8 \pm 10.7$ & $50.0 \pm 2.0^{* *}$ \\
Osmotic shock $(0.5 \mathrm{M} \mathrm{NaCl}, 15 \mathrm{mins})$ & $40.7 \pm 8.8$ & $50.0 \pm 3.6^{* *}$ \\
Osmotic shock $(0.5 \mathrm{M} \mathrm{NaCl}, 30 \mathrm{mins})$ & $24.2 \pm 12.4$ & $44.5 \pm 7.3^{*}$ \\
Oxidative stress $\left(2 \mathrm{mM} \mathrm{H} \mathrm{O}_{2}, 15 \mathrm{mins}\right)$ & $71.9 \pm 16.4$ & $73.4 \pm 8.2$ \\
Oxidative stress $\left(2 \mathrm{mM} \mathrm{H} \mathrm{O}_{2}, 30 \mathrm{mins}\right)$ & $45.7 \pm 14.7$ & $65.7 \pm 9.5^{*}$ \\
Acid shock $(\mathrm{pH} 3.0,15 \mathrm{mins})$ & $71.8 \pm 7.3$ & $86.3 \pm 3.9^{* *}$ \\
Acid shock $(\mathrm{pH} 3.0,30 \mathrm{mins})$ & $44.7 \pm 19.1$ & $61.0 \pm 8.6$ \\
Alkaline shock $(\mathrm{pH} 8.0,15 \mathrm{mins})$ & $73.7 \pm 14.7$ & $81.4 \pm 7.0$ \\
Alkaline shock $(\mathrm{pH} 8.0,30 \mathrm{mins})$ & $60.8 \pm 11.7$ & $80.3 \pm 5.3^{* *}$ \\
\hline
\end{tabular}

3 The values reported in the table are the averages \pm standard deviation of three measurements. The 4 significance of differences between groups was determined using the Mann-Whitney U test. ${ }^{*} \mathrm{p}<$ 50.05 was considered statistically significant. $* * p<0.01$ 6 